\title{
Culpa e cuidado no candomblé baiano
}

\author{
[ Guilt and care in the candomble of Bahia
}

\section{Clara Flaksman ${ }^{\mathrm{I}}$}

\begin{abstract}
Este artigo é uma versão ampliada da fala apresentada na mesa "Feitiçarias contrapolíticas, contrafeitiçarias políticas" na VI ReACT. Agradeço aos organizadores do evento; aos companheiros de mesa, Marina Vanzolini e Renato Sztutman, e ao debatedor Jean Tible, pelos comentários feitos na ocasião; e a Maria Cecilia Morais, pelas observações sobre psicanálise.
\end{abstract}

RESUMO - O objetivo principal deste artigo é discutir a inadequação de certos conceitos "nossos" para a descrição de realidades ancoradas em outras premissas. Após afirmar que, inicialmente, a preocupação constante da maioria dos filhos de santo que conheci com o risco de serem vitimados por algum feitiço me soava como paranoia, demonstro como essa noção está atrelada ao que o etnopsiquiatra Tobie Nathan denominou "sociedade de universo único" e é, portanto, inoperante no candomblé baiano. Ao final do artigo sugiro, com base em diversas situações vivenciadas durante a pesquisa de campo, que o termo "prevenção" é um descritor mais adequado para aquilo que eu, inicialmente, classificara como "paranoia”. · PALAVRAS-CHAVE • Candomblé; religiões afro-brasileiras; etnopsiquiatria; prevenção; Salvador, Bahia. • ABSTRACT · My aim in this paper is to discuss how inadequate some of "our" concepts are to describe other realities, based on different assumptions. The constant worries that my friends in candomblé had about the risk of becoming victims of sorcery initially sounded to me as a paranoid behavior. Thus, I try to show that the notion of paranoia has to do with "single universe societies", in the distinction proposed by ethnopsychiatrist Tobie Nathan. At the end of my paper, based on situations I experienced throughout my field research, I suggest that the term "prevention" would be a fitter description for the phenomenon I, at first, had classified as "paranoia". · KEYWORDS · Candomblé; Afrobrazilian religions; etnopsychiatry; prevention; Salvador, Bahia.

Recebido em I5 de dezembro de 2017

Aprovado em 3I de janeiro de 2018

FLAKSMAN, Clara. Culpa e cuidado no candomblé baiano. Revista do Instituto de Estudos Brasileiros, Brasil, n. 69, p. 307-323, abr. 2018.

DOI: http://dx.doi.org/Io.II606/issn.23I6-90IX.voi69p307-323

I Universidade Federal da Bahia (UFBA, Salvador, BA, Brasil). 
Logo que cheguei ao Gantois, terreiro de candomblé onde fiz a minha pesquisa de campo, em Salvador, me foi quase inevitável recair em uma antiga categoria psiquiátrica e psicanalítica e considerar o ethos local "paranoico". Tudo que acontecia a alguém era sempre culpa de outrem - a questão básica era identificar essa outra pessoa que lhe causara algum dano. Ao longo da minha pesquisa, testemunhei muitos episódios de extrema desconfiança por parte dos filhos de santo do Gantois. "A gente aqui é cismado", me disse uma filha de santo a certa altura². Ora desconfiavam que alguém estava roubando dinheiro, ora que estava mentindo, mas a suspeita mais frequente era de que alguém estaria "fazendo feitiço" (algumas vezes contra o próprio terreiro) 3 . O que mais me chamava a atenção era que essas acusações nunca tinham as consequências a que eu estava acostumada: uma acusação contra a pessoa a quem, em seguida, seria dada uma oportunidade de se defender, produzindo, na maioria das vezes, uma ruptura e, em ocasiões menos frequentes, um acerto de contas - ou seja, as acusações que ocorriam no terreiro não correspondiam ao que eu entendia como

2 Em uma reportagem à revista Fatos e Fotos, em março de I978, Mãe Menininha afirmou: "Eu sou descendente de africano, e africano, moço, é mais desconfiado do que índio. Eles, quando são amigos, são de verdade. Mas sempre ficam desconfiando".

3 Siqueira também se deparou com essa mesma questão em sua pesquisa de campo, no Baixo Sul baiano. Segundo ela, para "alguns autores, tais cismas, porque incessantes e cíclicas, configurariam uma relação paranoica: 'o outro' seria alguém de quem se desconfia. No presente trabalho [a sua tese de doutorado], ao contrário, deseja-se ressaltar o envolvimento de muitos 'outros', com quem se vivencia não só o temor, mas também a sua superação. Pois, além de prover os humanos de atenção à mentira, aos perigos, à vontade, à bondade, além de os dotar de uma agudeza ímpar de sentidos, este mundo da feitiçaria, com sua propensão para a guerra, envolve uma quantidade imensa de seres, cuja proliferação aponta, ao contrário do que pareceria a princípio, para a fugacidade”. SIQUEIRA, Paula. O sotaque dos santos: movimentos de captura e composição no candomblé do interior da Bahia. Tese (Doutorado em Antropologia Social). Rio de Janeiro, Universidade Federal do Rio de Janeiro, 20I2, p. I84-I85. Penso que a situação encontrada por Siqueira em muito se assemelha à vivenciada por mim, o que pode ser comprovado também no seguinte trecho de sua tese, em que um de seus interlocutores afirmar que a sua cisma é uma maneira de precaução: “Como tantas outras pessoas que encontrei na região, Mário não nega sua cisma. [...] É através dessa cisma - uma cisma que vem também de sua médium vidente - que Mário se considera precavido” (p. I84). 
acusação e nem tinham o desdobramento que eu imaginaria. As pessoas que conheci, em sua grande maioria, passavam o tempo todo com medo de serem atacadas. Não que os filhos de santo com quem convivi fossem medrosos, o que não poderia estar mais longe da realidade. As pessoas do candomblé que conheci são, no geral, extremamente corajosas. Mas, na grande maioria dos casos de suspeita, minha percepção legalista e quase jurídica dos fatos tendia a me fazer crer em uma ausência total das provas factuais e concretas que eu considerava necessárias. E em quase todos - para não dizer todos - havia o envolvimento de entidades sobrenaturais: nos ebós 4 , na busca de provas através do jogo de búzios, e nas resoluções. Em outras palavras, poderíamos dizer que as acusações envolviam sempre forças invisíveis. "Cuidado com a inveja”; "Ele fez um ebó para mim"; ou até: "Você tem que fazer ebó periodicamente, para não ser atingido". E chamo atenção para o termo usado: "atingido". Ele supõe que a pessoa deve estar sempre preparada contra um ataque, uma vez que coisas boas despertam inveja e é natural que o desejo alheio se volte contra quem as possui. As energias, tanto as boas quanto as más, como a inveja é entendida, são parte integrante desse universo, tanto quanto as entidades sobrenaturais. Circulam à nossa volta o tempo todo - e só olhos treinados, ou preparados de nascença para vê-las, são capazes de perceber quando se aproximam de nós. Às vezes, um olhar já basta: “O olho é o maior feitiço", me diziam. E contra o "olho" - a saber, contra a inveja - quase não há solução possível. A inveja, segundo me disseram muitos filhos de santo que conheci, é a pior de todas as forças, pois atua tanto como um feitiço direto (já que o olhar invejoso de alguém já basta como feitiço automático) quanto como grande motivação para a feitiçaria5. E tudo pode despertar a

4 Ebó, segundo me explicaram, significa, literalmente, “oferenda”. Portanto, um ebó pode ser feito tanto para o bem quanto para o mal. Existem ebós de limpeza, ebós de purificação, ebós de cura - ebós que geram benesses - e ebós que visam causar malefícios.

5 Devo advertir que minha intenção não é descrever e analisar práticas de feitiçaria, tornando-as inteligíveis em nossos próprios termos. Proponho aqui uma abordagem um pouco diferente das análises antropológicas tradicionais sobre o tema que, desde Evans-Pritchard (EVANS-PRITCHARD, Edward Evan. (I937). Bruxaria, oráculos e magia entre os Azande. Rio de Janeiro: Jorge Zahar, 2005), as tratam geralmente como variações de nossas próprias categorias - seja de acusação, seja de causalidade. Sobre isso, DOUGLAS, Mary (Ed.). Witchcraft, confessions and accusations. Londres: Tavistock Publications, I970; MAGGIE, Yvonne. Medo do feitiço: relações entre magia e poder no Brasil. Rio de Janeiro: Imprensa Nacional, I992; FRY, Peter. O Espírito Santo contra o feitiço e os espíritos revoltados: "civilização" e "tradição" em Moçambique. Mana, v. 6, n. 2, 2000, p. 65-95. Ao invés de seguir nessa direção, escolhi aqui - seguindo o caminho traçado por Tobie Nathan (NATHAN, Tobie; STENGERS, Isabelle. (I995). Médecins et Sorciers. Paris: Les Empêcheurs de penser en rond, 2004; NATHAN, Tobie. L'influence qui guérit. Paris: Éditions Odile Jacob, 200I) e prefigurado por Jeanne Favret-Saada (FAVRET-SAADA, Jeanne. Les mots, la mort, les sorts: la sorcellerie dans le Bocage. Paris: Gallimard, I977) - descrever o contraste entre o modo como as práticas associadas à feitiçaria apareciam para mim e o modo que foi sendo revelado pela investigação etnográfica, de maneira que esse segundo modo "perturbe" o primeiro ou, como bem definiu Goldman (GOLDMAN, Marcio. Da existência dos bruxos (ou como funciona a antropologia).R@U, v. 6, n. I, 20I4, p. 7-24. p. 20), desestabilize o nosso pensamento. O objetivo do artigo é, portanto, descrever o percurso desse encontro - com todos os equívocos que dele fizeram parte - e as suas consequências. 
inveja: o cônjuge, a roupa, o dinheiro, o amor, os bens materiais e imateriais. E contra a inveja é preciso o máximo de proteção ${ }^{6}$.

\section{MAPEANDO AS RELAÇõES}

Se entendermos que a pessoa no candomblé é formada pelo que vem de fora, pelas relações com o que lhe é a princípio exterior ${ }^{7}$ - familiares, entidades, sentimentos, elementos da natureza -, torna-se mais fácil compreender o complexo sistema de acusações que permeia o candomblé baiano. Sistema em que a acusação básica, como não poderia deixar de ser, é a de prática de feitiçaria ${ }^{8}$, seja direta ou indireta, ou mesmo intencional ou não intencional. Na ocorrência de algum evento, procura-se antes de mais nada visualizar o mapa das relações das pessoas envolvidas, e não as suas possíveis motivações ou sentimentos. Qualquer coisa que tenha feito ou que ainda faça parte de uma pessoa envolvida nos acontecimentos - suas palavras, um prato com seus restos de comida, suas roupas - é levada em conta nesse mapeamento e, muitas vezes, pode fornecer a chave para a sua resolução.

Na maioria das vezes, a acusação não admite possibilidade de defesa. O julgamento costuma ser rápido - normalmente, pede-se que alguém olhe nos búzios e confirme ou negue a culpa do outro. Uma vez constatada a culpa, o culpado é apontado (ainda que nem venha a tomar conhecimento disso), um ebó é feito para neutralizar os efeitos do suposto feitiço e a vida segue em frente.

Durante a pesquisa de campo, acompanhei, muito de perto, um caso de traição amorosa envolvendo duas pessoas muito próximas. A pessoa traída, ao se deparar com a situação, reagiu tratando imediatamente de construir um mapa com todas as relações dos envolvidos (especialmente os indivíduos com algum poder de interferir na realidade, como os pais e mães de santo). Primeiramente, listou quem poderia ter informações sobre o caso; em seguida, quais pessoas poderiam ter agido contra ou a favor do casal; depois, quem teria dito o que para quem. E em nenhum momento, ignorando as minhas muitas observações nesse sentido, levou em conta o que as pessoas envolvidas poderiam estar sentindo, por exemplo. Importava descobrir quem estaria por trás do ebó causador da traição. Enquanto, para mim, as motivações para

6 A proteção deve vir, inclusive, do potencial causador do malefício (que não deseja causar prejuízo). Como uma antiga filha de santo do Gantois me explicou, até um elogio da própria mãe pode fazer mal ao filho. Mas, para isso, há uma formulação específica que garante a proteção da criança: a mãe, ou quem quer que deseje elogiá-la, deve sempre exclamar “Benza Deus!” ao fim da congratulação. Assim, se se deseja dizer que a criança é bonita, por exemplo, deve-se afirmar: "Que bonita. Benza Deus!" e assim por diante.

7 Tomo aqui como referência o conceito de Goldman (GOLDMAN, Marcio. A possessão e a construção ritual da pessoa no candomblé. Dissertação (Mestrado em Antropologia Social). Rio de Janeiro, Universidade Federal do Rio de Janeiro, I984) sobre a noção de pessoa no candomblé (ver nota Io). Para uma análise mais extensa sobre o tema, ver também: FLAKSMAN, Clara. Relações e narrativas: o enredo no candomblé da Bahia. Religião e Sociedade, v. 36 n. I, 20I6, p. I3-33.

8 Termo raramente usado. Usa-se mais "está fazendo ebó para me prejudicar"; ou "está fazendo feitiço"; mas raramente se dá nome à prática. 
um fato dessa ordem deveriam vir de dentro (da esfera dos sentimentos, quaisquer que fossem), para ela a motivação só podia ser externa. E a análise que ela fazia é, na verdade, perfeitamente coerente com a noção de pessoa do candomblé. A pessoa formada por elementos exteriores expande-se horizontalmente, através das suas relações, e é mapeando essas relações que alguém se capacita a entender a totalidade de algum evento que lhe tenha ocorrido. Por isso, qualquer coisa que tenha feito ou que ainda faça parte de uma pessoa envolvida nos acontecimentos é levada em conta nesse mapeamento e, muitas vezes, acaba fornecendo a chave para a sua resolução.

Diversas vezes, ao longo da pesquisa, ouvi reprimendas pela minha "inocência". "Você não desconfia de ninguém", me disse certa vez uma filha de santo. "Tudo você acha que pode ter sido culpa sua. A culpa nunca deve ser sua não. Quando acontece alguma coisa com a gente, a gente não tem que ficar pensando 'o que foi que eu fiz?; isso é besteira. O que a gente tem que descobrir é quem fez isso com a gente.” Ou seja, no mundo do candomblé, a motivação dos acontecimentos geralmente também vem de fora. Assim como os orixás determinam nossas ações, os eventos e as forças são recebidos e modulados de acordo com a preparação de quem os recebe. Na ocorrência de algum evento, procura-se antes de mais nada visualizar o mapa das relações das pessoas envolvidas.

Seria adequado dar conta de tudo isso com o termo "paranoia”? Abordei a questão com alguns filhos de santo, que jamais concordaram com a minha avaliação. "Não é paranoia não, minha filha”, me disse um amigo: "O mundo é que é muito perigoso". Por que então, para mim, "paranoia” aparecia como o único descritor possível para a atmosfera que eu percebia naquele mundo? Como entender um mundo composto por tantas forças, tantas delas invisíveis, e descrever esse modo de vida em que devemos estar sempre preparados para nos defender? Que noções podemos usar para descrever esse tipo de existência?

\section{A paranoia e SEU Contexto}

"Paranoia" é um termo derivado do grego e cunhado pela psiquiatria a partir do latim científico paranoea, significando "turvação dos sentidos", aplicando-se aos distúrbios mentais em que se desenvolvem delírios persecutórios. Na linguagem corrente, esvaziado do rigor classificatório ou de um sentido estritamente psicopatológico, é usado num registro mais informal para descrever tanto a sensação pessoal de

9 É curioso que Nina Rodrigues tenha se debruçado sobre a questão da paranoia na população negra em dois artigos, publicados em 1903 em revistas de psiquiatria. Ele trata exclusivamente do sentido psicótico da paranoia (como discutirei mais adiante) e seu objetivo é provar que a paranoia, tida como doença de brancos até então, podia também aparecer na população negra, embora muitas vezes associada a questões de feitiçaria. NINA RODRIGUES, Raimundo. (I903). A paranoia nos negros: estudo clínico e médico-legal (parte I). Revista Latino-Americana de Psicopatologia Fundamental 2 (VII). Associação Universitária de Pesquisa em Psicopatologia Fundamental, Brasil, 2004, p. I6I-I78; NINA RODRIGUES, Raimundo. (I903). A paranoia nos negros: estudo clínico e médico-legal (parte 2). Revista Latino-Americana de Psicopatologia Fundamental 3 (VII). Associação Universitária de Pesquisa em Psicopatologia Fundamental Brasil, 2004, p. I3I-I58. 
sentir-se alvo de alguma perseguição, seja ou não fantasiosa, como, de maneira mais vaga, uma atmosfera geral em que predominam a suspeita e a desconfiança. Natural, assim, que a palavra me ocorresse para descrever a atmosfera de suspeita constante que eu percebia no terreiro.

Não pretendo aqui entrar em grande detalhe sobre a definição psiquiátrica ou psicanalítica da paranoia, tema extremamente complexo. Usarei apenas como referência um texto do psicanalista Charles Melman, discípulo de Lacan, para tentar situar o que, num sentido mais estrito, se entende como paranoia, sem pretender nenhuma precisão psicanalítica - e, mais do que isso, no intuito de melhor contrastá-la com o que creio que ocorre no candomblé. Segundo Melman ${ }^{\mathrm{Io}}$, reconhecem-se hoje dois quadros clínicos relacionados à paranoia: um mais propriamente patológico, ligado às doenças mentais, especialmente nos quadros de psicose, e outro mais relacionado à existência comum, como um traço constitutivo do sujeito - em suas palavras, "uma passagem necessária para a constituição do eu". A paranoia é entendida, portanto, como parte do processo de constituição do sujeito - o que torna o retorno à posição paranoide (ainda que desvinculada de uma estrutura propriamente psicótica, tal como definida na psicopatologia psicanalítica) uma possibilidade constante na vida de qualquer um. Já no caso da paranoia enquanto psicose, considera-se que essa "constituição do eu" não se deu de forma eficaz, deixando o sujeito mais propenso a ser deslocado e deixando-o mais exposto a se sentir abalado ou ameaçado em sua relação com o mundo que o cerca.

A principal característica de um estado de paranoia é a suposição constante de que outras pessoas nos tragam algum prejuízo. Nele, perde-se assim a interiorização do "outro" (como definido por Lacan), fundamental na construção do sujeito; percebe-se do lado de fora o que geralmente está dentro de cada um. Considerando que, na psicanálise lacaniana, segundo Melman, a internalização/incorporação do "Outro" em sua dimensão simbólica é indispensável para a aquisição de um "eu”, a paranoia pode ser considerada, assim, como uma visão externa desse "Outro" que, na verdade, também é "eu". Em outras palavras, supõe-se que a constituição do eu se dá por meio da relação com essa alteridade externa, de uma maneira que permita simultaneamente a apropriação e a alienação de sua imagem, em uma dimensão tanto imaginária quanto simbólica - o "eu" e o "Outro" seriam, portanto, espaços que se distinguem e se articulam internamente ao sujeito, espaços necessários para a estrutura subjetiva que assim se organiza. A alteridade externa é uma espécie de "fora-dentro", assim como o nosso próprio inconsciente: algo que é, a um só tempo, estrangeiro e íntimo. E essa dimensão do "eu" como imagem adquirida, imaginada, é encoberta na existência cotidiana por um "véu" que garante a existência plena do sujeito, aderido, assim, à ilusão de um "eu" absoluto e sob controle. A paranoia como fenômeno transitório seria, portanto, a suspensão desse véu, localizando a intenção malévola nesse "Outro" que nos é externo - não num grau extremo como no caso da psicose, em que ocorre a separação absoluta entre o "eu" e o "Outro", mas

Io MELMAN, Charles. Questões acerca da paranoia. In: A clínica da psicose: Lacan e a psiquiatria 2 (4): As

Paranoias. Rio de Janeiro: Tempo Freudiano Associação Psicanalítica, 2005. 
numa relação dialética e sutil. O fenômeno patológico, segundo esse ponto de vista, consistiria na degradação de um equilíbrio presente na estrutura básica do sujeito.

Uma característica dessa teoria é de que não existe identidade pura, e sim um composto, estrutura semelhante à que encontrei no candomblé baiano ${ }^{\text {II }}$. Porém, na psicanálise considera-se que esse "Outro" tem uma dimensão inconsciente (e por vezes se confunde com o próprio inconsciente), lugar de onde emergem sentimentos e palavras cuja origem não se conhece. O “eu”, assim, seria uma ilusão - mas uma ilusão necessária para a vida cotidiana. Ainda que sejamos regidos, na verdade, por esse "Outro" que nos habita, precisamos acreditar em nossa capacidade de reger a própria vida. Pois esse "Outro" que nos conduz é vazio, e somos nós os responsáveis pelas atitudes que tomamos regidos por esse impulso alheio a nós.

Ora, se na estrutura normal do sujeito sempre há um "Outro", que ele precisa incorporar para poder viver livre de neuroses graves, o que fazer quando existe uma dissociação entre esses dois "componentes da pessoa"? Pois se existe um outro que se manifesta através de nós, e por cujas atitudes somos responsáveis, é de esperar que possamos levar a vida sem pensar nisso com tanta frequência. Para Melman, esse "Outro" só apareceria - ou seria invocado - em situações específicas: o sonho, o ato falho, a psicanálise. No resto do tempo, permaneceria encoberto pelo véu que assegura a ilusão de integridade individual de que precisamos.

Ou seja, nas considerações psicanalíticas sobre a paranoia existe apenas um único personagem, embora não se possa vê-lo como uma unidade sólida e indissociável, dotado de fronteiras bem definidas, o que poderíamos até aproximar da figura da pessoa composta do candomblé. Mas a agência, nesse caso, é sempre da pessoa do "eu", ainda que faça parte dela um "Outro" que para ela mesma é desconhecido. Trata-se de um "Outro”, entretanto, que está dentro de nós.

Pois a situação que encontrei no candomblé não podia ser mais diferente. Em um mundo "multiagencial”, esse "Outro" que, segundo a psicanálise, governa o "eu”, é um "outro" - ou melhor, são "outros" - no sentido pleno do termo, sobre cujas atitudes não temos qualquer controle. Se a noção de pessoa pode aproximar a psicanálise e o candomblé, a de sujeito (como responsável, em última instância, por tudo que o afeta -ou, ao menos, como o postulante de agências, ainda que inconscientes ou mesmo incontroláveis) parece separar de maneira irremediável esses dois universos.

II Muitos autores que se dedicaram ao estudo das religiões de matriz africana no Brasil usam o modelo arquetipal para se referir à noção de pessoa característica do candomblé, argumentando que os orixás são na verdade arquétipos da personalidade humana, usados como um modelo no qual a pessoa se baseia e ao qual se limita. Cada indivíduo se identificaria com um orixá, e isso aplacaria os conflitos de sua própria personalidade, que assim se encaixaria em um modelo preexistente representado ao limite nos rituais de possessão. Marcio Goldman inovou a discussão apresentando o argumento de que os orixás, antes de serem modelos de personalidade, são, eles mesmos, parte da pessoa. Segundo ele, a pessoa no candomblé é formada ao longo de sua feitura, de acordo com as entidades que passam a fazer parte de sua cabeça. Esses componentes espirituais são variáveis; no caso do terreiro estudado por Goldman, são os sete orixás que formariam o “carrego de santo" (o conjunto de orixás que alguém leva na cabeça), um erê, um egum e um exu. GOLDMAN, Marcio, I984, op. cit. No Gantois, essa composição não é tão rígida, mas a maneira de formação da pessoa é exatamente a mesma. 
Ou seja, mais que "multiagencial", o mundo do candomblé é composto por forças que não podem deixar de se afetar mutuamente. E, nesse caso, a noção de paranoia, de fato, não faz sentido. $\mathrm{O}$ que ali se via em jogo, na verdade, era uma gama de fatores que eu não estava acostumada a considerar. $\mathrm{O}$ que me deixava com um problema de linguagem: como encontrar um termo capaz de dar conta dessa sensação? Afinal, para que serve um conceito? Pode-se utilizá-lo fora de seu contexto? Quão amplo pode ser seu alcance, especialmente em universos (literalmente) distintos? Era necessário, portanto, tratar as ideias das pessoas com quem convivi sem alinhá-las a um termo preexistente, inoperante naquele contexto. Qual seria, então, a gramática apropriada para isso?

\section{UNIVERSO ÚNICO E UNIVERSO MÚLTIPLO}

Foi ao entrar em contato com as ideias do etnopsiquiatra Tobie Nathan que a questão começou a se esclarecer para mim. Nathan ${ }^{\mathrm{I2}}$ identificou que, na psicoterapia ocidental (que ele chama de "erudita"), "o homem está sozinho", enquanto, na psicoterapia que ele denomina "selvagem", o homem está sempre acompanhado ${ }^{\mathrm{r} 3}$. E, enquanto na psicoterapia "erudita" o terapeuta é o mestre do saber racional, na "selvagem" ele é o "mestre dos saberes ocultos". Partindo dessa premissa, Nathan diferencia dois tipos de sociedade: a de universo único e a de universos múltiplos. Na sociedade de universos múltiplos, toda doença geralmente se deve à ação de alguma entidade não humana. O doente não é visto sozinho, isolado da sociedade, desligado de seu pertencimento. Ao contrário, ele é incluído numa categoria grupal de pessoas com questões semelhantes às suas. $\mathrm{O}$ ato terapêutico não interroga a doença, mas os objetos relacionados ao universo oculto. Parte-se do princípio de que o universo é povoado por uma multiplicidade de seres, e o dispositivo divinatório é sempre um ato de criação: é ele que institui, torna palpável e ponderável a interface entre os universos, pois somente ele tem acesso a esse mundo oculto (e desconhecido). Por isso mesmo, o método é arriscado: ao contrário da psiquiatria ocidental, para a qual o médico está sempre certo, o "terapeuta selvagem" se expõe a vários riscos cada diagnóstico que faz ${ }^{\mathrm{T}}$. Segundo Nathan, porém, isso não representa um grande

I2 NATHAN, Tobie; Isabelle STENGERS, op. cit.

I3 Embora reconheça que as práticas a que Nathan se refere como psicoterapias podem ser, em alguns casos, distintas da psicanálise (especialmente a lacaniana, onde o próprio saber e a racionalidade aparecem associados ao inconsciente do sujeito), generalizo sua distinção considerando que na psicanálise, assim como nas psicoterapias citadas pelo autor, o “Outro” é um lugar que está vazio (e, no caso da psicanálise, deve ser ocupado temporariamente pelo psicanalista para permitir o seu encontro pelo sujeito - e o posterior reconhecimento, pela parte dele, de que é essa dimensão inconsciente que está no comando).

I4 Nas palavras de Nathan: "Sendo invisíveis, eles são incognoscíveis por natureza. Desse modo, se o processo terapêutico se revela ineficaz, isto não será nunca um sinal de incompetência do terapeuta, mas da vontade de permanência das forças invisíveis. Assim, não existe nesse caso, stricto sensu, o erro terapêutico, somente as tribulações do invisível... E pode ser isso que explica os longos percursos necessários para que se livrem das suas doenças”. NATHAN, Tobie; Isabelle STENGERS, op. cit. (tradução minha). 
problema, pois a maior preocupação do saber selvagem é com o tratamento, e não com a doença. Ou seja, se o paciente ficar curado, o caso estará resolvido ${ }^{15}$, independente de qualquer consideração técnica ${ }^{\mathrm{I} 6}$. Além disso, Nathan chama a atenção para o caráter de contágio presente nesses sistemas terapêuticos: cada diagnóstico é discutido e passado adiante pelos pacientes e as pessoas que se relacionam com eles, formando um quadro parecido com o que observei no caso do mapeamento horizontal de uma traição amorosa.

Segundo Nathan, a medicina ocidental é feita para tratar pessoas "de universo único", ou seja, que vivem em um mundo onde o caráter de agente se restringe apenas aos seres humanos (e talvez a alguns animais); já os terapeutas não ocidentais tratam pessoas que vivem em um mundo "multiagencial" ele afirma, a pessoa está contida em seu sintoma, e o processo de identificá-lo torna os dois inseparáveis (tendo como consequência afastar a pessoa do convívio social). Já o "terapeuta selvagem" começa seu tratamento por dissociar o sintoma da pessoa, associando-o a fatores externo ${ }^{18}$. A resposta à doença, portanto, segue quatro etapas:
[...] a aplicação deste princípio desencadeia sempre sequências complexas que associem quatro elementos:
I) a constatação do distúrbio;
2) o postulado da intencionalidade do invisível;
3) a explicitação dessa intenção;

I5 Segundo Nathan, "Não se trata de discutir o grau de verdade da interpretação, mas observar a consequência de sua aplicação”. Ibidem, p. 65 (tradução minha).

I6 Ou seja, segundo Nathan a questão está na eficácia, e não na crença, da mesma maneira que com o candomblé: “O que fazer então com a noção de 'crença'?, pergunta o seu suposto interlocutor. Abandoná-la, responde ele sem delongas, e "substituí-la pelo seguinte postulado: toda ação culturalmente definida - um ritual, um sacrifício, uma oferenda, uma proteção... I) é de fato o que pretende ser; 2) é geralmente eficaz para o que concerne sua definição . [...] Portanto, essas ações prescindem de interpretação. Se aceitarmos esse postulado, o trabalho do observador ficará ao mesmo tempo mais simples e de mais fácil compreensão, pois obrigará o observador a reconstituir o sistema de pensamento presente na origem da ação culturalmente definida, mesmo que se trate de um pensamento não-analítico, um pensamento em atos...”. Ibidem, p. $5 I$ (tradução minha). Ele nos diz ainda que "A partir do momento em que abandonamos a noção de crença, somos também obrigados a abandonar a noção de símbolo. [...] É a noção de símbolo que nos impede de considerar os terapeutas 'não eruditos' como autênticos pensadores técnicos”. Ibidem, p. 53-54 (tradução e grifos meus).

I7 "Numa cultura não ocidental, um medicamento é um objeto ativo que permite crer, manter e depois perenizar a disjunção entre o sintoma e a pessoa. Um medicamento é portanto um objeto que permite concretizar a teoria que professa a natureza comum da desordem.[...] No nosso mundo, na psiquiatria, um medicamento é também um objeto ativo que permite crer, manter e depois perenizar o contrário: dessa maneira, ele trata da junção entre o sintoma e a pessoa. Um comprimido de Largactyl é, desse modo, um medicamento, pois cumpre a teoria segundo a qual a esquizofrenia se encontra no interior do sujeito". Ibidem, p. IoI (tradução e grifos meus).

I8 "A consequência da aplicação de um pensamento selvagem para resolver uma desordem é sempre dissociar o sintoma da pessoa. E, para chegar a esse objetivo, todos os pensamentos selvagens que conheço recorrem a um mesmo grande princípio: a atribuição de uma intencionalidade ao invisível". Ibidem, p. 63 (tradução e grifos meus). 
4) a sequência mais importante, muitas vezes a única visível para um observador: a resposta adequada, sempre endereçada ao invisível ${ }^{\mathrm{Ig}}$.

A consequência seguinte desse tipo de tratamento, segundo Nathan, é a formação de grupos de pessoas assoladas pelo mesmo mal. Além disso, nesse sistema nenhuma doença é desconhecida; os seres invisíveis é que podem sê-lo.

Da mesma forma, Nathan ${ }^{20}$ traça um paralelo entre os diagnósticos "eruditos" (nesse caso, especialmente os de Gilles de La Tourette e Freud) e os "selvagens" sobre o pavor ("la frayeur"). Segundo ele, a etimologia da palavra "frayeur" apresenta uma "bipolaridade semântica", pois significa ao mesmo tempo "invasão" e "extração" Nas terapias "selvagens", os casos/surtos de pavor costumam estar associados a um processo de separação entre a alma e o corpo, ou ao encontro com algum elemento de um universo radicalmente dissociado do seu. Essa "captura" seria causada, nos países africanos, por surtos de pavor; já entre os povos ameríndios, por processos profundos de tristeza; e, em certos grupos, resultaria em certos comportamentos estereotipados de mimetismo, ocasionados, em última instância, por essa perda da identidade ocasionada pelo pavor ${ }^{22}$. Ou seja, um surto de pavor, nas terapias "selvagens", é sempre resultado de um encontro, de uma interação. Já nas terapias "eruditas", o pavor é resultado ou de um problema neurológico (geralmente hereditário, segundo Tourette) ou da angústia fundamental do ser humano (segundo Freud). Em ambos os casos, a motivação do pavor é sempre individual, fruto de características internas do sujeito. Ainda que resultante de um processo traumático, a cura do medo sempre estaria dentro do sujeito, tornando-o assim responsável pelo seu destino ${ }^{23}$. Porém, para Nathan, a saída de Freud foi associar a angústia e o pavor, indicando que a angústia seria uma espécie de preparação para que a pessoa não fosse capturada pelo "horror", ou seja, uma proteção contra ele - tirando dessa maneira definitivamente o pavor da teoria psicanalítica ${ }^{24}$. Pois, segundo Nathan, "Admitir o pavor como afeto central no funcionamento psíquico obrigaria a pensar que o outro nos invadia, nos influenciava, nos modificava, chegando mesmo a nos metamorfosear"25.

Embora Nathan não chegue a formular nesses termos, fica evidente que a saída encontrada pela psicanálise freudiana (a opção pela angústia) e pela psiquiatria de Tourette (a opção pela genética) é uma saída de "sociedades de universo único", e aplicável somente a elas. Já as terapias "selvagens”, segundo ele aponta, têm mais

I9 Ibidem, p. 67 (tradução minha).

20 NATHAN, Tobie, 200I, op. cit.

2I Ibidem, p. 201 (tradução minha).

22 Ibidem, p. 202 (tradução minha).

23 Segundo Nathan, "Assim Freud escapa, como Gilles de La Tourette, como os neurologistas modernos, do segundo termo da etiologia do pavor, o da invasão. Resta, porém, a questão da interface que o trauma sempre coloca - para a qual evidentemente não há escapatória - a inalienável questão do outro”. Ibidem, p. 2I3 (tradução minha).

24 Ibidem, p. 2I/ (tradução minha).

25 Ibidem, p. 2I5 (tradução minha). 
recursos para lidar com os surtos de pavor, justamente pela sua capacidade de associar certos fenômenos à influência de outrem. Ou seja, as "sociedades de universo múltiplo" teriam, nesse caso, um arsenal de instrumentos mais eficazes para lidar diretamente com o pavor, já que são capazes de incorporar em seus diagnósticos a interferência de outras entidades, possíveis causadores de um encontro traumático.

Nos termos de Nathan, os filhos de santo com quem convivi também habitam um "universo múltiplo". Não faz sentido, portanto, nesse tipo de situação, empregar o termo "paranoia" - noção cunhada pela psiquiatria e, assim, totalmente associada ao "universo único". Por isso o que eu dizia era sempre refutado: num universo múltiplo e perigoso, não faz sentido o pressuposto de uma ameaça vinda de um "Outro" que, na verdade, está contido em cada um. A ameaça, como tudo o mais, vem de fora.

\section{UM NOVO CONCEITO}

Outra dimensão do ebó, além de seu aspecto propriamente curativo, ou seja, de reação a algo - como vimos anteriormente -, é a prevenção. “Ebó é profilático", me explicou certa vez um amigo de Salvador. "Não precisa ter acontecido nada para fazer ebó não. A gente tem que fazer ebó sempre!" Ele refutava a minha negativa em fazer um ebó, já que eu achava que nada estava acontecendo. Segundo me explicou: "Tem sempre alguma coisa acontecendo, minha filha”. Suas palavras se assemelham ao que me disse um pai de santo de Sergipe, quando estive em seu terreiro:

O feitiço oferece mais perigo para quem desconhece. E para quem sabe, mas não faz nada para se proteger. Conhece o ditado? O pior cego é aquele que não quer ver. Você tem que se proteger sempre. Isso não quer dizer que alguém tenha feito um ebó para você. Basta que elas tenham inveja, e pronto, o mal já está feito ${ }^{26}$.

Durante toda a minha pesquisa, ouvi recomendações quanto à minha desproteção. "Você fica circulando por aí", me disse uma filha de santo do Gantois, "e você não é feita, pode pegar alguma coisa estranha”. Eu não estava preparada: meu corpo não tinha como filtrar as energias que poderiam entrar, não fora feito para aquele tipo de coisa, como me diria ela. "Quando a gente é feito, tem proteção", me disse outro filho de santo. "Você está aí desprotegida, pode pegar qualquer coisa."

Qual seria, portanto, o termo que eu poderia usar para descrever esse tipo de situação? A noção de paranoia, como vimos, não corresponde em nada ao que dizem os filhos de santo. Segundo eles, o mundo é de fato perigoso - e estamos sempre sujeitos a um ataque, direto ou indireto. A noção de paranoia, da forma como eu a usava, podia ser definida como "preocupação constante com o mal que alguém possa lhe fazer": o que corresponde à realidade do mundo do candomblé, mas só até esse ponto. A semelhança não vai além porque, no universo do candomblé, o mal que

26 Quando lhe contei que uma inundação tinha acontecido na minha casa, ele disse: "Ainda bem que está entrando água! Para lavar tudo o que é ruim!". 
pode ser feito envolve outros fatores, que eu não levava em consideração (já que na paranoia como entendida à luz dos estudos psicológicos "ocidentais", como vimos, ele seria um reflexo do próprio imaginário do sujeito). No candomblé, a preocupação é palpável, concreta, referida a algo real. Penso que é preciso estar familiarizado com os termos provenientes desse contexto particular para entender as sutilezas do pensamento e as indicações trazidas nas declarações que me deram.

Assim, parti em busca de um termo que pudesse exprimir esse sentimento, essa atenção praticamente constante em relação à possibilidade de um ataque. Pensei, primeiramente, em "cuidado": "é importante ter cuidado", ou "tomar cuidado", diziam sempre as pessoas do candomblé. Entretanto, no candomblé, o termo "cuidado" tem outro sentido: quando se diz que alguém precisa assentar o santo, por exemplo, ou mesmo cumprir alguma obrigação menor, o termo usado é sempre "cuidar". "Você está precisando cuidar deste ori”, me disse uma mãe de santo. "Você precisa assentar o santo para poder cuidar dele direitinho", disse outra mãe de santo a uma pessoa que eu acompanhava. O termo cuidado, assim, é utilizado até menos no sentido de "cautela" ou "prudência", como em "tomar cuidado", do que no sentido de "zelo", "responsabilidade", como em "cuidar de um doente", "prestar cuidados". Depois me ocorreu utilizar o termo "defesa", já que escutei muitas vezes que eu deveria "me defender", tanto no sentido de garantir o que me seria devido em alguma circunstância quanto no sentido de me proteger de algum ataque contra mim. Porém "defesa" se refere tanto à defesa prévia quanto à reação a um ataque, o que não condiz com o termo que eu procurava. Terminei por decidir que o melhor termo para substituir o que eu até então descrevia como paranoia seria “prevenção". A ideia de prevenção sempre esteve muito presente durante a minha pesquisa. Ouvi muitas vezes que era muito importante eu me prevenir: "Você tem que se prevenir, não pode ficar andando por aí sem conta", foi uma das frases que escutei muito no início da pesquisa, antes de ganhar meu primeiro colar de contas ${ }^{27}$.

O conceito de prevenção caminha junto com a ideia de vulnerabilidade. Stengers e Pignarre ${ }^{28}$ definiram o capitalismo como um sistema feiticeiro, que usa a descrença de suas vítimas como arma $^{29}$. Todos corremos o risco de nos tornarmos subordinados ao sistema capitalista, mesmo os que se julgam protegidos (por seu próprio pensamento crítico, por exemplo). Somos todos presas em potencial, somos todos vulneráveis. E, principalmente, os que foram capturados (e tiveram a sua alma roubada) não têm consciência disso. Os autores afirmam que

[...] a questão de conhecer os riscos é crucial, pois é o que dá valor pragmático ao diagnóstico de feitiçaria que estamos arriscando fazer. Todo o pensamento sobre

27 Colar de contas consagradas que os fiéis do candomblé usam no pescoço.

28 STENGERS, Isabelle; PIGNARRE, Philippe. La sorcellerie capitaliste. Paris: Éditions La Découverte, 2007.

29 'O próprio ato de nomear o capitalismo como feitiçaria transforma a relação com os 'outros' que supomos ser supersticiosos. Pensar que ninguém precisa de proteção é o tipo de imprudência que, aos olhos dos 'outros' notadamente supersticiosos, se parece muito com a ingenuidade mais perigosa: aos seus olhos, como consequência disso, o desastre se torna perfeitamente previsível. O risco pragmático consiste em aceitar a hipótese desse desastre, ou seja, transformar as questões de nossa vulnerabilidade e aprendizado nas precauções necessárias, como um problema crucial”. Ibidem, p. 40 (tradução minha). 
feitiçaria se encaminha para o risco de se confrontar suas operações e da necessidade de se proteger, pois o perigo da captura está sempre presente. Aquele que se acredita seguro, aquele que acredita não necessitar de proteção, torna-se uma vítima em potencial ${ }^{30}$.

Segundo o diagnóstico de Stengers e Pignarre, um dos perigos para aqueles que lutam contra o capitalismo é sofrerem de dois males a ele relacionados: a paranoia - quando supomos que o capitalismo é, afinal, responsável por tudo que nos assombra; e a depressão - quando concluímos que nada que fizermos será capaz de mudar o estado das coisas. Além disso, a paranoia - ou melhor, a conclusão de que algo não passaria de paranoia - enfraqueceria ainda mais o potencial de defesa da vítima. Somos todos vulneráveis, eles nos dizem, e podemos ser capturados a qualquer momento ${ }^{3 \text {. }}$ É necessário ter conhecimento do perigo e tomar medidas ativas de proteção. Muitas vezes, em Salvador, disseram-me que a pessoa precisava ter consciência dos perigos para poder se proteger. "A pessoa mais facilmente atingível é aquela que acha que não tem nada do que se proteger”, me diziam.

Penso, portanto, que o a noção de "paranoia" poderia ser substituída pelo conceito de prevenção, mais coerente com a noção de pessoa do candomblé. Um dia, declarei a uma filha de santo do Gantois que não me sentia ameaçada. "Você que não vê", ela me garantiu. Quando reafirmei que raramente achava que alguém quisesse me fazer mal, ela riu tanto que quase caiu da cadeira onde estava sentada. A pessoa prevenida está, portanto, sempre mais consciente dos perigos do mundo. A prevenção é, de certa maneira, um aguçamento dos sentidos, uma visão ampla, múltipla, irrestrita, indispensável no mundo multiagencial do candomblé. Prevenir-se, ou proteger-se, é uma ação que resulta em - mas também reforça - um modo de atenção aguçada para os perigos, ativando a capacidade de visualizar e de mapear a rede de relações na qual se está inserida e ver o que não é imediatamente perceptível. Mas não somente isso: a pessoa prevenida torna-se capaz de responder aos perigos presentes nesse fluxo constante de acontecimentos de forma mais efetiva e eficiente.

\section{“BEM-VINDA AO NOSSO MUNDO”}

"Bem-vinda ao nosso mundo", me disse a mãe pequena ${ }^{32}$ do Gantois quando lhe contei a série de sonhos que eu vinha tendo nos últimos dias. "Agora você está começando a ver o mundo como a gente vê." Sonhos são maneiras de ter acesso ao "outro mundo", ela me explicou. Podemos ver neles com clareza o que está lá, dar uma espiada numa vida plena, o quadro completo que existe em outro plano da existência. Mas também servem como meio, um caminho através do qual as entidades se comunicam com

30 Ibidem, p. 45 (tradução minha).

3I Para uma análise mais extensa sobre a obra de Stengers e Pignarre, ver o artigo de Renato Sztutman que integra este volume.

32 Mãe pequena ou iaquequerê é a filha de santo que geralmente responde pelos assuntos cotidianos de uma casa de candomblé, a segunda na hierarquia do terreiro. 
os humanos. E também podem ser mensagens, que precisam ser decifradas com a ajuda de especialistas, de preferência alguém que consiga acessar essa totalidade extraterrena por outros meios, como o jogo de búzios.

Muito do candomblé vem através de sonhos: às vezes de maneira direta, às vezes de maneira indireta. Entretanto, os sonhos nunca devem ser contados à noite, para não permitir qualquer mistura ou confusão entre os dois mundos. Existe um paralelo evidente entre os pares vigília e sono, dia e noite, vida e morte, domínios que nunca devem entrar em contato. Certa vez compareci a um axexêe, a cerimônia mortuária do candomblé, e posteriormente comentei com uma pessoa que também havia estado lá que havia achado a festa bonita. "Bonita para eles”, ela me disse, enfatizando o para eles. "Para eles. Você nunca deve dizer que achou bonita uma festa que é para os mortos. É bonita para eles. Você não quer ser confundida. Tome cuidado.”

É importante marcar as diferenças, especialmente diante dos não humanos, para que eles não nos tomem por quem não somos. Por exemplo, no terreiro, as mulheres sempre devem usar saia. Logo que cheguei, a primeira providência da mãe de santo do Gantois foi mandar fazer uma saia para mim. Uma saia que pode ser vestida por cima da roupa, sempre pela cabeça, nunca pelos pés. “O uniforme”, como me diziam algumas filhas de santo, em tom de galhofa. Mas o motivo de sua utilização é sério: a saia é a única maneira de Exu saber quem é homem e quem é mulher, explicou-me uma filha de santo. Por isso, dentro do terreiro, as mulheres devem estar sempre de saia; não querem ser tomadas por homens, "uma energia tão diferente".

Da mesma forma, é importante contar sempre os sonhos para a mãe de santo: é ela quem vai determinar a natureza do sonho, se é uma revelação, um recado, um deslocamento do corpo físico, uma aparição. Por isso, logo depois de falar com a mãe pequena do terreiro sobre os sonhos que havia tido, e seguindo as indicações dela, fui conversar com a mãe de santo. Primeiro contei-lhe o meu primeiro sonho: uma adolescente, toda vestida de preto, sentada na minha cama, me fitava com um olhar profundo. Tive a nítida sensação de que ela estava mesmo presente, de que eu estava acordada e não sonhando. "Você estava no entremundos", ela me explicou depois. Quando acordei, achei que o sonho era um reflexo do quanto eu andava impressionada com as experiências pelas quais vinha passando. Na noite seguinte, sonhei que caminhava com minha família pela beira de uma represa e um enorme peixe tentava atacar um de meus familiares. Eu pegava um remo que estava ao meu alcance e batia no peixe até matá-lo. Acordei com as costas e o braço doídos, como se de fato tivesse travado uma luta corporal com alguém. Na terceira noite, sonhei que várias crianças de branco aglomeravam-se no ar, bem em cima da minha cabeça, novamente olhando para mim.

A mãe de santo ouviu o meu relato em silêncio, assentindo com a cabeça em alguns momentos. Quando acabei de falar, ela me disse: “É, esses sonhos da menina e das crianças, esses me preocupam. Você me dá licença, mas eu vou olhar ljogar os búzios] para ver o que eles querem. Agora, este sonho do peixe, esse é psicanalítico. Você procure um terapeuta para te ajudar".

O que ela fez, em primeiro lugar, foi separar os universos: dois dos sonhos pertenciam ao universo dos mortos, dos espíritos, do além; o outro, não. Em poucas palavras ela estabeleceu a diferença entre os mundos: um vinha de fora, era o mundo 
sobre o qual ela teria alguma ingerência, sobre o qual iria consultar os búzios, verificar se havia alguma mensagem que pudesse decifrar; o outro vinha de dentro, do meu inconsciente. E para a mãe de santo não havia qualquer dúvida. Um desses universos remetia ao exterior, a forças externas - e estava em seu domínio. Sobre os dois sonhos correspondentes ela podia me fornecer um diagnóstico preciso: olhar nos búzios e descobrir de que tipo de entidade se tratava, se queriam alguma coisa de mim, ou se vinham me transmitir algum recado. $O$ outro não: este teria que ser tratado numa outra instância.

Para ela, portanto, os dois mundos estão lado a lado. A divisão entre universo único e universo múltiplo, nesse caso, não é absoluta, como nos casos analisados por Tobie Nathan. Ou melhor, uma mãe de santo é capaz de adicionar o que nós consideramos um "universo único" como apenas mais um dos "universos múltiplos”. Além disso, ela consegue rapidamente diferenciar a qual universo pertence determinado evento - assim como foi capaz de, em um instante, diferenciar os mundos aos quais cada sonho dizia respeito.

A diferença estabelecida pela mãe de santo do Gantois diz muito daquilo que tento retratar aqui: a pessoa no candomblé, como já foi dito, é formada por forças, influências, relações que lhe são exteriores. A mãe pequena do terreiro, ao me dar suas boas-vindas, deu-me também uma primeira pista para entender o funcionamento desse mundo: um mundo onde humanos e não humanos vivem em relação constante ${ }^{33}$.

O universo do candomblé compreende forças, entidades e energias ausentes da realidade na qual eu estava acostumada a viver. É um universo em que a ação das forças pode ser percebida e vista, e no qual existem instrumentos que permitem lidar com elas, modulá-las e, de certa forma, controlá-las. Ao mesmo tempo que, dentro desse universo, a pessoa passa a ter consciência dessas forças que nos assolam, adquire também instrumentos que lhe permitem defender-se delas e controlá-las até certo ponto. Através da produção de um assentamento ${ }^{34}$, ou mesmo por meio do ato de dar comida a algum orixá, a pessoa pode promover um ajuste, uma modulação de seus componentes, evitando que sejam atacados ou defendendo-os no caso de sofrerem a ação de forças contrárias. O fato de ser cismado, no caso, está ligado a essa capacidade de visão. Quem está dentro desse universo é, muitas vezes, capaz de ver essas forças em ação, ao contrário de quem está fora.

33 Jim Wafer fala da interação com os espíritos que conheceu durante sua estada na Bahia. Segundo ele, cada vez mais vamos conhecendo as entidades e entendendo suas distintas personalidades, acompanhando suas histórias e nos envolvendo com elas. WAFER, Jim. The taste of blood: spirit possession in Brazilian candomblé. Philadelphia: The University of Pennsylvania Press, I99I.

34 Produção do orixá individual como um duplo concreto que pode ser manipulado, cuidado e alimentado. 


\section{CONCLUSÃo}

No candomblé, parte-se do princípio fundamental de que as pessoas são permeáveis às forças do mundo ${ }^{35}$. E são essas mesmas forças que, devidamente controladas, as formam. O "corpo fechado" faz referência antes de tudo a um corpo capacitado a filtrar o que deve ou não deve atravessá-lo.

Os filhos de santo com quem convivi sempre me diziam que o candomblé parte da aceitação da natureza humana com todos os seus meandros. Aceita a maldade como parte constituinte do ser humano. "Não há como querer catequizar o mundo", me dizia sempre um pai de santo com quem tive a chance de conviver. Ao contrário, deve-se aprender a lidar com a maldade e, principalmente, a se defender dela - que sempre há de estar presente. E a pessoa não saber, ou fingir que não sabe, da presença da maldade é ainda pior: o conhecimento da maldade é necessário para a defesa. Não é possível levar uma vida de paz sem tomar as devidas precauções. Ou, como me disse um amigo do candomblé repetidas vezes, quando conversamos sobre esse assunto: "Todo mundo é bom, mas o meu capote sumiu".

Logo que cheguei ao Gantois, conheci uma filha de santo que achava muita graça de eu me achar culpada por coisas que aconteciam comigo. "Que nota! Não dá para ser amigo de todo mundo não" - ela me dizia. Depois de algum tempo fui vítima de um mal-entendido, e tentei pensar de acordo com essa lógica. "Isso aí!", me disse essa filha de santo. “Lá ela! Lá ela!”, me disse, referindo-se à outra pessoa envolvida no mal-entendido, querendo dizer que eu deveria mantê-la a uma distância segura. "Lá ela!" ou “Lá ele!" são expressões muito usadas pelos meus amigos do candomblé de Salvador, falando de alguém de quem preferem manter distância por acreditarem que essa pessoa poderia causar-lhes algum mal.

Juntamente com a aceitação do mal, e penso que até mesmo como seu complemento, está a celebração da vida. A ideia de movimento é fundamental no candomblé: uma postura ativa é necessária perante a vida e os eventos que a compõem. A aceitação do mal, nesse caso, não equivale de modo algum à aceitação das consequências que ele pode produzir: aceita-se a existência do mal, mas luta-se bravamente contra os seus efeitos. Ou, como nos dizeres de uma mãe de santo que conheci: "Enquanto uns oram e vigiam, a gente faz ebó. É preciso não apagar o carvão nunca”.

35 O que está, segundo me explicaram, no fundamento do resguardo, quando a pessoa que passou por algum ritual deixa de comer e fazer certas coisas por certo período de tempo. Como naquele momento o corpo ainda não é capaz de fazer a filtragem dessas forças, antes é necessário que o que foi feito "se assente” para que a proteção funcione. 
CLARA FLAKSMAN é doutora em Antropologia Social pela Universidade Federal do Rio de Janeiro (UFRJ) e pósdoutoranda no Programa de Pós-Graduação em Ciências Sociais da Universidade da Bahia (PPGCS/UFBA).

E-mail: claramflaksman@gmail.com

\section{REFERÊNCIAS BIBLIOGRÁFICAS}

DOUGLAS, Mary (Ed.). Witchcraft, confessions and accusations. Londres: Tavistock Publications, I970.

EVANS-PRITCHARD, Edward Evan. (I937). Bruxaria, oráculos e magia entre os Azande. Rio de Janeiro: Jorge Zahar, 2005.

FAVRET-SAADA, Jeanne. Les mots, la mort, les sorts: la sorcellerie dans le Bocage. Paris: Gallimard, I977. . Ser afetado. Cadernos de Campo, n. I3, 2005, p. I55-I6I.

FLAKSMAN, Clara. Relações e narrativas: o enredo no candomblé da Bahia. Religião e Sociedade, v. 36, n. I, 20I6, p. I3-33.

FRY, Peter. O Espírito Santo contra o feitiço e os espíritos revoltados: "civilização" e "tradição" em Moçambique. Mana, v. 6, n. 2, 2000, p. 65-95.

GOLDMAN, Marcio. A possessão e a construção ritual da pessoa no candomblé. Dissertação (Mestrado em Antropologia Social). Rio de Janeiro, Universidade Federal do Rio de Janeiro, I984.

. Da existência dos bruxos (ou como funciona a antropologia).R@U, v. 6, n. I, 20I4, p. 7-24.

MAGGIE, Yvonne. Medo do feitiço: relações entre magia e poder no Brasil. Rio de Janeiro: Imprensa Nacional, I992.

MELMAN, Charles. Questões acerca da paranoia. A clínica da psicose: Lacan e a psiquiatria 2 (4): As Paranoias. Rio de Janeiro: Tempo Freudiano Associação Psicanalítica, 2005.

NATHAN, Tobie. L’influence qui guérit. Paris: Éditions Odile Jacob, 2001.

NATHAN, Tobie; STENGERS, Isabelle. (I995). Médecins et sorciers. Paris: Les Empêcheurs de penser en rond, 2004. NINA RODRIGUES, Raimundo. (I903). A paranoia nos negros: estudo clínico e médico-legal (parte I). Revista Latino-Americana de Psicopatologia Fundamental 2 (VII). Associação Universitária de Pesquisa em Psicopatologia Fundamental, Brasil, 2004, p. I6I-I78. . (I903). A paranoia nos negros: estudo clínico e médico-legal (parte 2). Revista Latino-Americana de Psicopatologia Fundamental 3 (VII). Associação Universitária de Pesquisa em Psicopatologia Fundamental, Brasil, 2004,p. I3I-I58.

SIQUEIRA, Paula. O sotaque dos santos: movimentos de captura e composição no candomblé do interior da Bahia. Tese (Doutorado em Antropologia Social). Rio de Janeiro, Universidade Federal do Rio de Janeiro, 2012.

STENGERS, Isabelle; Philippe PIGNARRE. La sorcellerie capitaliste. Paris: Éditions La Découverte, 2007.

SZTUTMAN, Renato. Reativar a feitiçaria, retomar a terra e outras receitas de resistência - Pensando com Isabelle Stengers. Revista do Instituto de Estudos Brasileiros, n. 69, abr. 2018.

WAFER, Jim. The taste of blood: spirit possession in Brazilian candomblé. Philadelphia: The University of Pennsylvania Press, I99I. 